\title{
ASPIRAÇÕES PELO ENSINO SUPERIOR PÚBLICO E A LEI DAS COTAS
}

Ana Paula Karruz

D Catharina MelloII

I Universidade Federal de Minas Gerais (UFMG), Belo Horizonte (MG), Brasil; apkarruz@gmail.com

II Secretaria de Estado de Planejamento e Gestão de Minas Gerais (Seplag); Universidade Federal de Minas Gerais (UFMG), Belo Horizonte (MG), Brasil; catharinacsm@hotmail.com

\section{Resumo}

Este artigo objetiva examinar desigualdades socioeconômicas e raciais nas aspirações pelo ensino superior público e avaliar se a Lei das Cotas as modificou. A formação de aspirações educacionais depende dos recursos disponíveis ao jovem, estando propensa a reproduzir desigualdades. Com base em um modelo empírico que articula contribuições da Psicologia, Sociologia e Economia da Educação, testamos a hipótese de que as cotas aumentam a aspiração pelo ensino superior público entre os elegíveis às vagas reservadas. A identificação de efeitos baseia-se num experimento natural e utiliza dados do Enem de 2012 a 2016 de residentes da região de Belo Horizonte, Minas Gerais. Os resultados alinham-se à expectativa, e revelam que os efeitos das cotas parecem ser moderados pelo sexo do estudante.

\section{DESIGUALDADE SOCIAL • EDUCAÇÃO SUPERIOR • COTAS • JUVENTUDE}

\section{ASPIRATIONS TO PUBLIC HIGHER EDUCATION AND THE "QUOTAS LAW"}

\section{Abstract}

This article examines socioeconomic and racial inequalities in the aspirations to public higher education and assesses whether Brazil's "Quotas Law" changed those aspirations. The formation of educational aspirations depends on the resources available to the youth; thus, it is prone to reproduce inequalities. Based on an empirical model that articulates contributions from Psychology, Sociology and Economics of Education, we tested the hypothesis that quotas increase the aspiration to public higher education among those eligible for reserved seats. Effect identification is based on a natural experiment; we use individual-level data from Belo Horizonte Metropolitan Area (Minas Gerais state), extracted from Enem 2012 to 2016 microdata. Results are in line with expectations; also, they indicate that quotas' effects vary by gender. 


\section{LA LEY DE CUPOS Y LAS ASPIRACIONES POR LA EDUCACIÓN SUPERIOR PÚBLICA Resumen}

Este artículo tiene el propósito de examinar desigualdades socioeconómicas y raciales en las aspiraciones por la educación superior pública y evaluar si la Ley de Cupos las modificó. La formación de aspiraciones educativas depende de los recursos disponibles al joven, y sigue la tendencia de reproducir desigualdades. A partir de un modelo empírico que articula contribuciones de la Psicología, Sociología y Economía de la Educación, investigamos la hipótesis de que los cupos aumentan la aspiración por la educación superior pública entre los elegibles a las plazas reservadas. La identificación de los efectos se basa en un experimento natural y utiliza datos del 2012 al 2016 del Enem de residentes en la región de Belo Horizonte, Minas Gerais. Los resultados se alinean a la expectativa, y revelan que los efectos de los cupos están en función del sexo del estudiante.

DESIGUALDAD SOCIAL • EDUCACIÓN SUPERIOR • CUOTAS • JUVENTUD

\section{ASPIRATIONS AUX ÉTUDES UNIVERSITAIRES PUBLIC ET LA LOI SUR LES QUOTAS \\ Résumé}

Cet article vise à examiner les inégalités socio-économiques et raciales à partir des aspirations à accéder à l'université à évaluer si la loi sur les quotas les a modifiées. La formation d'aspirations éducatives dépend des ressources mises à la disposition des jeunes et peut être susceptible de reproduire les inégalités. Ancrés sur un modèle empirique qui regroupe des contributions de la Psychologie, de la Sociologie et de l'Économie de l'Éducation, nous avons testé l'hypothèse selon laquelle les quotas renforcent les aspirations d'accéder à l'enseignement supérieur public des ayant-droit. L'analyse des effets se base sur une expérience naturelle et utilise les données de l'Enem de 2012 à 2016 de résidents dans la région de Belo Horizonte, Minas Gerais. Les résultats sont conformes aux attentes et révèlent que les effets des quotas varient selon le sexe.

INÉGALITÉ SOCIALE・ENSEIGNEMENT SUPÉRIEUR・QUOTAS・JEUNESSE 

pelo ensino superior público (ESP) entre jovens concluintes do ensino médio e avalia se o esquema de reserva de vagas instituído pela Lei das $\operatorname{Cotas}^{1}(\operatorname{Ldas} \mathrm{C})$ modificou essas aspirações. Para tanto, focamos no caso da Universidade Federal de Minas Gerais (UFMG), uma universidade de projeção nacional e excelência, mas que capta seus estudantes localmente, dominando o mercado de instituições de ensino superior (IES) públicas na Região Metropolitana de Belo Horizonte (RMBH). ${ }^{2}$

Aspirações educacionais foram e continuam sendo reputadas como importantes preditores do alcance educacional (Coleman et al., 1966; Jacob \& Wilder, 2010; Schneider \& Saw, 2016). Notadamente, a formação de aspirações constitui um processo sensível ao influxo informacional e de outros recursos disponíveis ao jovem. Portanto, está propensa a reproduzir desigualdades sociais - o que impõe uma condição de contorno às escolhas educacionais futuras. Em um estudo sobre a UFMG, Soares e Júdice (2003) reportaram baixa participação de egressos de escolas estaduais no vestibular, o que, segundo os autores, é fruto de um processo de autoexclusão. No contexto brasileiro, no entanto, esse tema tem sido pouco explorado.

A LdasC definiu quatro segmentos de acesso (modalidades) para egressos do ensino médio público. A modalidade 1 (M1) contempla pretos, pardos e indígenas de baixa renda. A modalidade 2 volta-se aos candidatos de outra cor/raça, também de baixa renda. As modalidades 3 e 4 não requerem comprovação de renda, sendo que pretos, pardos e indígenas concorrem na modalidade 3, e os de outra cor/raça, na modalidade 4. A ampla (ou livre) concorrência (modalidade 5, M5) atende os oriundos (total ou parcialmente) do ensino médio privado.

Uma análise da LdasC não pode ignorar dois aspectos fundantes, ainda que não obrigatórios, dos processos seletivos para ingresso no ensino superior ocorridos na última década: a utilização do Exame Nacional do Ensino Médio (Enem) como teste de entrada (em uma vasta gama de IES públicas e privadas) e do Sistema de Seleção Unificada (SiSU), como plataforma de inscrição, simulação e seleção de candidatos ao ESP. Cerca de um quarto das vagas oferecidas por IES públicas no país são alocadas via $\mathrm{SiSU}$, com base nas notas obtidas no Enem ${ }^{3}$ (Instituto Nacional de Estudos e Pesquisas Educacionais Anísio Teixeira [Inep], 2019). Na primeira edição do SiSU 2020, foram oferecidas 237.128 vagas em 128 IES públicas de todo o país. ${ }^{4}$

Dada a ampla adesão ao Enem como teste de entrada, os examinados não estão, de antemão, definindo estreitamente as instituições para as quais concorrerão. Com o SiSU, a decisão sobre cursos a que se candidatar acontece posteriormente à divulgação das notas obtidas no Enem, e o sistema permite alterar as opções de instituição e curso até o fechamento das inscrições, além de oferecer simulações das notas de corte durante o período de inscrição. Os custos de inscrição nos processos seletivos, combinados com a incerteza de admissão, são determinantes nas tomadas de decisão por

1 Lei Federal n. 12.711/2012, doravante LdasC.

2 A LdasC foi alterada pela Lei Federal n. 13.409 (2016), que estendeu a reserva de vagas para pessoas com deficiência. Na UFMG, essa ampliação de público-alvo foi implementada no primeiro semestre de 2018.

3 Cálculo nosso.

4 Segundo o Censo da Educação Superior 2018, o mais recente disponível em Minas Gerais, foram oferecidas 52.229 vagas em IES públicas (34.978 delas preenchidas via Enem) e 276.156 em privadas (Inep, 2019). Desde o primeiro semestre de 2014 , todas as vagas da UFMG são distribuídas via SiSU, exceto cursos com vestibular por habilidades (área das Artes), vagas adicionais para indígenas e outras ofertas específicas. 
parte dos concluintes do ensino médio, de modo que a centralização desse processo no SiSU implicou a redução de tais custos. Ademais, as simulações realizadas antes do fechamento do sistema permitem aos candidatos ajustarem suas escolhas de curso e de instituição, de modo a maximizar as chances de aprovação (Machado \& Szerman, 2016; Nogueira et al., 2017).

Todavia, mesmo no grupo de examinados pelo Enem, há heterogeneidades quanto às ambições de transição para a graduação. Essa condição pode ser aferida pelo questionário aplicado no momento da inscrição, que apresenta um conjunto de itens com a seguinte redação:

Indique os motivos que levaram você a participar do Enem ( 0 indica o fator menos relevante e 5 o fator mais relevante):

i. Ingressar na Educação Superior Pública;

ii. Ingressar na Educação Superior Privada;

iii. Conseguir uma bolsa de estudos (ProUni, outras); e

iv. Participar do Programa de Financiamento Estudantil - Fies.

Na medida em que IES públicas tendem a oferecer um ensino de melhor qualidade ${ }^{5}$ e a gozar de maior prestígio social, a análise desses itens permite inspecionar se as aspirações de ingresso no ESP variam entre grupos socioeconômicos e raciais e se o advento das cotas se associa a alguma variação nessas aspirações. Apesar de bastante elevado o interesse nas instituições públicas, análises descritivas (detalhadas à frente) demonstram diferenças não negligenciáveis. Entre residentes da $\mathrm{RMBH}$, concluintes do ensino médio examinados no Enem 2012 a 2016 e elegíveis à M1 (egressos do ensino médio público, com renda familiar per capita inferior a 1,5 salário mínimo, e autodeclarados pretos, pardos ou indígenas), 80,4\% manifestaram alto interesse no ESP, versus $92,3 \%$ na M5 (frequentadores do ensino médio privado). ${ }^{6}$

Diante do exposto, este artigo objetiva compreender os condicionantes das aspirações educacionais pelo ESP, a magnitude de possíveis desigualdades socioeconômicas e raciais nessas aspirações, bem como avaliar se, e em que medida, a reserva de vagas no ensino superior federal transforma tais aspirações. Para tanto, a próxima seção recorre à literatura internacional sobre formação de aspirações educacionais. A partir da adaptação de trabalhos da Psicologia (Eccles, 2009; Korhonen et al., 2016), Sociologia (Bourdieu, 1974/2007; Schneider \& Saw, 2016) e Economia da Educação (Hoxby \& Avery, 2013; Hoxby \& Turner, 2013; Jacob \& Wilder, 2010; Oreopoulos \& Dunn, 2013), desenvolvemos um modelo empírico. Esse modelo pressupõe que a formação de aspirações quanto ao ensino superior é sensível a uma variedade de fatores individuais (por exemplo, desempenho acadêmico), familiares (por exemplo, renda, escolaridade parental), da comunidade (município de residência), da escola (dependência administrativa) e do investimento (por exemplo, riscos associados a diferentes alternativas de IES).

Com base nesses aportes teóricos, propomos três hipóteses e uma abordagem metodológica para exame do caso da UFMG (Seção 3). Sinteticamente, as hipóteses preveem que seja mais provável que examinados de melhor preparo acadêmico almejem o ESP; que seja menos provável que elegíveis à M1 tenham tal ambição; e que a LdasC eleve essa aspiração entre elegíveis à M1, ao passo que a deprima entre aqueles disputando vagas na M5. A quarta seção apresenta os resultados - os quais se mostraram, de modo geral, alinhados às expectativas. A quinta seção sumariza o esforço e as conclusões, sendo sucedida pelas referências.

5 No "Emerging economies university rankings 2020" (Times Higher Education, 2020), dentre as dez instituições brasileiras mais bem posicionadas, apenas duas são privadas (em terceiro e décimo lugares). No topo da lista estão Universidade de São Paulo (USP) (em primeiro lugar), Universidade Estadual de Campinas (Unicamp), Pontifícia Universidade Católica do Rio de Janeiro (PUC-Rio) e Universidade Federal de Minas Gerais (UFMG), esta em quarto lugar.

6 Tomando-se uma operacionalização mais abrangente das aspirações, a qual considera resposta 4 ou 5 como indicativa de alta importância do ingresso no ESP entre as motivações para prestar Enem, o percentual de examinados na amostra com aspirações dessa natureza é de 89,6\% e 95,7\% na M1 e na M5, respectivamente. 


\section{Condicionantes das aspirações pelo ensino superior}

A formação de aspirações educacionais para o ensino superior tem sido abordada por diferentes disciplinas. A Psicologia da Educação enfatiza o papel de dois conjuntos de percepções na formação da identidade, e nas ações por ela motivadas - entre as quais, a aspiração pelo ensino superior (Eccles, 2009). O primeiro concerne à percepção de valores intrínsecos à experiência da graduação, que combina preferências próprias e aquelas estimuladas pelo grupo social de referência. $\mathrm{O}$ segundo refere-se à noção de autoconceito, em particular autoconceito acadêmico (neste caso, quão capazes nos sentimos para enfrentar os desafios da educação terciária). Assim, a aspiração pelo ensino superior reflete uma gama diversa de fatores, entre eles classe social, gênero, incentivo de pais e professores, senso de pertencimento ao ambiente universitário, desempenho acadêmico e aptidões (Korhonen et al., 2016).

Em um estudo sobre jovens finlandeses na faixa de 15 a 16 anos, Korhonen et al. (2016) identificaram padrões de formação de aspirações educacionais demarcados por gênero. Em particular, gênero parece mediar a influência do desempenho acadêmico em Matemática e do interesse por essa disciplina: o desempenho acadêmico em Matemática mostrou-se um preditor estatisticamente significante das aspirações de meninos (mas não das meninas), ao passo que o interesse por Matemática se revelou preditor das aspirações de meninas (mas não de meninos).

$\mathrm{Na}$ Sociologia da Educação, o tema vem sendo tratado há pelo menos 50 anos, quando foi analisado no relatório Equality of Educational Opportunity, conhecido como Relatório Coleman (Coleman et al., 1966). À época, negros estadunidenses declaravam aspirações mais altas de frequentar a educação terciária que brancos, embora a aspiração do primeiro grupo não se convertesse proporcionalmente em matrícula. Atualmente, o quadro se mantém, com a diferença de que os níveis de aspiração e de matrícula no ensino superior aumentaram em todos os segmentos populacionais. Para compreender esse padrão continuado de desigualdade, Schneider e Saw (2016) mobilizam argumentos presentes no Relatório Coleman sobre a formação de aspirações. Entre eles, a asserção de que as condições macrossociais subsequentes à Lei dos Direitos Civis (Civil Rights Act, 1964), ao ampliarem as oportunidades de trabalho a negros graduados (por exemplo, como professores, burocratas), configuraram uma importante oportunidade de mobilidade social, catapultando as aspirações educacionais do grupo.

Hoje, a maioria dos adolescentes estadunidenses vê o ensino superior como uma condição quase que necessária, embora não suficiente, para a inserção profissional, o que eleva as aspirações pela educação terciária em todos os grupos raciais/étnicos. Entretanto, o caminho entre o interesse e a matrícula é atualmente mais desafiador, requerendo um investimento considerável em informação sobre instituições, cursos e programas de assistência, pontuam Schneider e Saw (2016).

A Economia da Educação explorou o tema a partir dos condicionantes das expectativas educacionais e do comportamento de candidatura (application) para o ensino superior, com ênfase em assimetrias informacionais e na qualidade do pareamento (matching) entre candidato e instituição.

Jacob e Wilder (2010) examinam a relação entre expectativas educacionais de concluintes do ensino fundamental e frequentadores do ensino médio e seu alcance educacional. Note que os autores preferem o termo "expectativas" a "aspirações"; segundo eles, aspirações são desejos, esperanças sobre o que acontecerá, enquanto expectativas são expressão do que os indivíduos pensam que acontecerá. Entre outras razões, Jacob e Wilder (2010) embasam tal predileção terminológica no entendimento de que em relação a aspirações, expectativas são mais permeáveis a um processo de atualização racional, à medida que o indivíduo adquire informação nova. 
Acreditamos que os itens do questionário socioeconômico do Enem considerados na presente pesquisa não são aspirações nem expectativas, em um sentido estrito, localizando-se em algum ponto entre esses dois conceitos. ${ }^{8}$ Ainda assim, reputamos como particularmente relevante o modelo conceitual elaborado por Jacob e Wilder (2010). Os autores elencam um leque variado de influências sobre as expectativas educacionais, apuradas em estudos conduzidos por psicólogos, sociólogos e economistas, e as organizam em cinco categorias: fatores individuais, familiares, da comunidade, da escola e dos custos. Embora esses autores não se debrucem em detalhes sobre cada um dos pilares, nenhum outro trabalho de nosso conhecimento foi tão abrangente em sua caracterização de expectativas em relação ao ensino superior.

A análise empírica empreendida por Jacob e Wilder (2010) reforça achados de estudos anteriores. Status socioeconômico e habilidade (medida por desempenho em testes padronizados) são positivamente relacionados a expectativas educacionais e se configuram como os principais condicionantes delas, embora o poder preditivo desses fatores venha se abrandando ao longo do tempo.

Outro resultado de interesse é que estudantes tendem a alterar suas expectativas ao longo do ensino médio e logo após concluí-lo, à medida que adquirem informação sobre seu potencial de sucesso na graduação, explicam Jacob e Wilder (2010). O movimento mais frequente se dá no sentido do rebaixamento, convertendo a expectativa de concluir pelo menos um bacharelado para a expectativa de ter pelo menos alguma exposição ao ensino superior. Novamente, status socioeconômico e desempenho acadêmico (medido por nota média na escola e performance em teste padronizado, ambos apurados no ano final do ensino fundamental) predizem alteração de expectativas, sendo que jovens em desvantagem socioeconômica ou acadêmica tendem a atualizar expectativas mais frequentemente; também, homens tendem a alterar expectativas ao longo do ensino médio mais vezes que mulheres.

Diversos trabalhos têm apontado o papel da (des)informação na conformação de expectativas sobre o ensino superior e no espectro de instituições e cursos considerados. Oreopoulos e Dunn (2013), em um experimento de campo com cinco escolas de ensino médio em regiões desfavorecidas de Toronto (Canadá), apuraram que estudantes expostos a um vídeo sobre benefícios da educação terciária e a informação sobre assistência financeira reportaram maiores retornos esperados do ensino superior e mostraram menos preocupações sobre custos e maior interesse em completar a educação terciária.

De fato, a desigualdade de recursos informacionais tem sido apontada como fator crucial para explicar diferentes padrões de comportamento entre jovens americanos de alto desempenho acadêmico e baixa renda. Nesse grupo, há os que buscam IES seletivas, compatíveis com seu potencial educacional (achievement-typical), enquanto outros se candidatam a instituições menos seletivas, majoritariamente frequentadas por indivíduos de performance escolar mais modesta e de menor renda (income-typical). Esse segundo grupo experimenta undermatching - ou seja, um pareamento subótimo de suas altas habilidades e o nível acadêmico, não tão rigoroso, da instituição. Hoxby e Avery (2013, p. 47, tradução nossa) listam cinco possíveis explicações para o comportamento de estudantes income-typical:

i. eles não poderiam arcar com os custos de instituições compatíveis com seu preparo acadêmico [instituições peer];

ii. eles são na verdade mais desfavorecidos [economicamente] que estudantes achievement-typical e, portanto, comportam-se diferentemente destes;

iii. eles tenderiam a não ser aprovados pelas instituições peer e teriam dificuldades para prosperar academicamente nelas, caso se candidatassem;

iv. eles são insuficientemente informados sobre suas oportunidades de frequentar o ensino superior; 
v. eles têm condições culturais, sociais ou familiares que os fazem desinteressados em se candidatar a instituições peer, mesmo que estejam confiantes em sua admissão e sucesso acadêmico subsequente.

Explicações (i) e (ii) são refutadas por Hoxby e Avery (2013), com base em análises descritivas. Quanto a (i), estudantes income-typical pagam mais para frequentar instituições menos seletivas do que desembolsariam em instituições peer, porque instituições mais seletivas têm feito investimentos pesados em assistência estudantil, de modo a se tornarem acessíveis aos candidatos aprovados de baixa renda. No tocante a (ii), Hoxby e Avery (2013) apuraram que, embora suas famílias também se encontrem no quartil mais baixo de renda, estudantes income-typical tendem a apresentar renda familiar ligeiramente superior à dos achievement-typical. Também, os pais de indivíduos income-typical possuem mais anos de escolaridade, em média.

Hipóteses (iii) e (iv) são rigorosamente testadas por Hoxby e Turner (2013). Essas autoras examinaram se estudantes income-typical alterariam seu comportamento se soubessem mais sobre IES. Ainda, desenvolveram uma maneira custo-efetiva de possibilitar a esses indivíduos uma visão panorâmica do conjunto de oportunidades de ensino superior a seu alcance. Para tanto, atribuíram aleatoriamente intervenções - pacotes de informações semipersonalizadas e/ou isenções de taxa de inscrição - a 39.677 estudantes, 7.749 dos quais constituíram um grupo de controle (participaram do estudo, mas não receberam as intervenções). A um custo de seis dólares por estudante, o tratamento de Hoxby e Turner (2013) levou indivíduos de alto desempenho e baixa renda a se candidatarem e serem aprovados para mais instituições, especialmente aquelas academicamente mais fortes, com taxas mais altas de graduação e mais recursos instrucionais. Confirmaram, assim, a explicação (iv). Por sua vez, (iii) é inteiramente refutada: as notas dos estudantes no grupo de tratamento mostraram-se tão elevadas quanto as daqueles no grupo de controle.

Em contraste com as hipóteses anteriores, (v) não é diretamente testável, apontam Hoxby e Avery (2013). Em essência, (v) implica que

[e]studantes income-typical estão fazendo escolhas bem informadas e racionais sobre o ensino superior. A utilidade que alcançam ao frequentar instituições não seletivas ou menos seletivas excede a utilidade que derivariam ao frequentar instituições mais seletivas. (Hoxby \& Avery, 2013, p. 36, tradução nossa).

Por exemplo, a razão para optar por uma instituição menos seletiva pode ser sua proximidade, permitindo assim que o estudante cuide de seus pais. Outra consideração aventada pelos autores refere-se a fatores culturais e sociais; por exemplo, o indivíduo pode acreditar que teria uma vida social mais satisfatória se frequentasse uma instituição com estudantes de origem similar. Em virtude do exposto, (iv) e (v) prosseguem como as principais hipóteses de causa do undermatching no contexto estadunidense.

Indubitavelmente, o advento do SiSU simplifica e barateia a application, ${ }^{9}$ além de diminuir a probabilidade de undermatching (via simulações e iterações na escolha de cursos e instituições). Ainda assim, os achados de Hoxby e Avery (2013) e Hoxby e Turner (2013) são relevantes para se pensar as aspirações de inscritos no Enem, manifestadas antes da prova e da ciência das notas obtidas no exame. Consideremos as hipóteses apreciadas naqueles trabalhos. No Brasil, o ESP é gratuito, e isso é uma informação que, acreditamos, seja conhecida entre os examinados no Enem - o que refuta (i). Hipótese (ii) não é descartada a priori, pois é possível que os examinados que não demonstram aspiração de frequentar o ESP sejam mais desfavorecidos socioeconomicamente em relação a contrapartes que

9 A participação no SiSU é gratuita para todos os interessados. Pessoas de baixa renda e matriculados no último ano do ensino médio de escolas públicas têm direito à gratuidade da inscrição do Enem. Em 2012, primeira edição do Enem considerada nas análises adiante, 61,5\% dos inscritos obtiveram isenção (Estadão.edu, 2012). Em 2019, esse percentual foi de 58,5\% (Bermúdez, 2019). 
manifestem tal aspiração. Quanto a (iii), na ocasião da inscrição no Enem, o indivíduo deverá contar com fatos e percepções passadas, portanto não informadas por seu desempenho no exame vindouro e cegas da nota de corte que o próximo processo seletivo imporá aos seus cursos de interesse (ainda que tenha ciência da nota de corte do processo anterior). Sobre o desempenho no ensino superior, a evidência acumulada é que, uma vez admitidos, beneficiários de ações afirmativas (sociais ou raciais) apresentam maior permanência e notas compatíveis às de não beneficiários (Takahashi et al., 2015; Valente \& Berry, 2017; Wainer \& Melguizo, 2018), mas essa informação pode não ser de conhecimento geral. Tais condições suportam a hipótese (iii).

Sobre (iv), nosso entendimento é que deficiências informacionais sejam constritoras das aspirações educacionais de jovens brasileiros. Primeiramente, é razoável esperar que a quantidade de aconselhamento oferecido no ensino médio seja bastante heterogênea entre escolas. Evidência etnográfica nesse sentido é provida por Maia (2019), que analisou a forma como o Enem é abordado em escolas de ensino médio da rede pública estadual localizadas em Belo Horizonte. Segundo, apesar de a informação sobre a gratuidade do ESP ser relativamente bem difundida, é possível que potenciais candidatos sobrestimem outros custos (e.g., com material didático, transporte), e desconheçam auxílios disponíveis (e.g., assistência estudantil, bolsas de iniciação científica).

Os fatores culturais e sociais subjacentes a (v) são tratados de forma residual por Hoxby e Avery (2013), não tendo sido examinados em minúcia; todavia, cremos que sejam pertinentes. Mesmo o SiSU tendo aumentado a informação disponível no momento da seleção de cursos e instituições, é defensável a noção de que a apreciação de benefícios potenciais, custos e riscos de cada alternativa seja tingida pela origem social do estudante. Essa visão apoia-se no conceito de disposições incorporadas (Bourdieu, 1974/2007), segundo o qual a decisão entre possibilidades de investimento (incluindo o educacional) não é enunciada como uma escolha livre, mas sim restrita a um cardápio limitado, contendo apenas as alternativas mais frequentes para pessoas de uma certa origem social.

As disposições incorporadas (Bourdieu, 1974/2007) configuram uma justificativa potencial para a primeira parte de (v), na medida que culminam no aparente desinteresse por instituições mais seletivas. Contudo, esse substrato teórico descola-se da segunda parte daquela hipótese. Não se trata de rejeitar uma IES seletiva a despeito da confiança no sucesso posterior. Trata-se de considerar tão improváveis a admissão e o atendimento às exigências acadêmicas e tão proibitivos os custos (de adequação ao meio e de um eventual fracasso) que o retorno esperado desse investimento, avaliado à luz de informação incompleta e da posição futura provável, dadas as condições sociais iniciais, aparenta ser pouco atrativo.

De todo modo, da análise das cinco potenciais explicações para o comportamento income-typical elencadas por Hoxby e Avery (2013), a única descartada a priori no caso do ESP brasileiro seria a primeira, dos custos do serviço. O exercício empírico incorporará diferentes medidas de renda familiar, a nota obtida no Enem e a escolaridade parental - considerando, assim, (ii), (iii) e (v). Já a proposição (iv) não poderá ser inspecionada diretamente com os dados disponíveis.

Apesar de originarem-se de tradições variadas, as perspectivas sobre a formação de aspirações referenciadas nesta seção compartilham premissas fundamentais. Primeiro, todas reconhecem a importância do acesso à informação sobre o ensino superior. Segundo, todas posicionam o jovem em seu meio, apontando interações capazes de promover maiores ou menores níveis de ciência do ensino superior, das vias de acesso a ele, de vivências na universidade e dos retornos esperados: ou seja, por meio de convivências na família, na escola e na comunidade.

Admitidamente, o valor intrínseco atribuído ao ensino superior, instruído parcialmente por preferências e pendores individuais (Eccles, 2009; Korhonen et al., 2016), não pode ser observado nos dados disponíveis para a realização deste trabalho (microdados do Enem). Igualmente, essa fonte nada revela da percepção dos inscritos quanto a custos, benefícios e riscos de diferentes alternativas de ensino superior - fatores explorados pelos economistas da Educação e que constituem a base informacional, 
desigualmente distribuída, das disposições incorporadas de Bourdieu (1974/2007). Entretanto, os microdados do Enem retratam outros aspectos relevantes à formação de aspirações, entre eles: preparo acadêmico (desempenho no exame), escolaridade dos pais, renda familiar, experiências na escolarização formal, município de residência e interesse pelo ensino superior privado. Consequentemente, o modelo empírico delineado na próxima seção tratará não de noções como motivações baseadas em preferências ou expectativas de retorno, mas de atributos do examinado e de seu meio que são considerados indutores de primeira ordem dessas considerações mais complexas, ainda que incapazes de exauri-las.

\section{Hipóteses e estratégia empírica}

Esta seção inicia-se pela enunciação das hipóteses testadas no presente trabalho, e prossegue descrevendo a estratégia analítica empregada. Reconhecemos, porém, que a própria elaboração das hipóteses é constrangida pela disponibilidade de dados. Dessa forma, convém principiar pela apresentação da variável dependente, e, onde cabível, mesclar reflexões teóricas com outras de caráter tático, referentes às possibilidades práticas de aproximação aos fenômenos relevantes teoricamente.

As aspirações pelo ESP, nossa variável dependente, são operacionalizadas por um indicador binário, o qual assume valor 1 para examinados motivados a perseguir a educação superior pública - i.e., para indivíduos que assinalaram a alternativa 5 no item "Indique os motivos que levaram você a participar do Enem (0 indica o fator menos relevante e 5 o fator mais relevante): i) Ingressar na Educação Superior Pública”. Caso contrário, a variável dependente é igual a zero.

Os já mencionados altos níveis de aspiração pelo ESP ensejam reflexão sobre eventual viés de desejabilidade social. Esse viés constitui uma tendência a oferecer respostas que são percebidas como socialmente desejáveis ou apropriadas, em detrimento de respostas que reflitam com maior exatidão o sentimento do entrevistado (Grimm, 2011). IES públicas são cobiçadas por oferecerem um serviço gratuito e de qualidade tipicamente superior. Nesse sentido, é possível que respondentes tenham se sentido compelidos a apontar uma alta importância do ingresso no ESP em sua decisão de prestar Enem por entenderem que essa era a atitude "esperada", socialmente desejável.

Porém, sendo o instrumento de coleta preenchido online, sem intermediação de um entrevistador, a probabilidade de que a desejabilidade social tenha influenciado as respostas é menor (Grimm, 2011). E o fato de haver uma diferença substantiva no padrão de resposta de diferentes grupos indica que, caso a desejabilidade social tenha inflado nossa medida de aspirações pelo ESP, o fez de maneira a não eliminar a variabilidade entre grupos. Notadamente, essa variabilidade é identificável em pergunta correlata sobre a rede privada. Inqueridos sobre a importância do ingresso no ensino superior privado como motivação para prestar o Enem, 48,3\% dos examinados elegíveis à M1 e 30,9\% dos elegíveis à M5 assinalaram 5. ${ }^{10}$ Assim, reforça-se a evidência de um padrão próprio ao grupo, em que o interesse pela rede pública é maior que o interesse pela rede privada em ambas as modalidades, porém M1 mostra aspiração mais baixa pela rede pública e mais alta pela rede privada em comparação com M5.

Tendo descrito a variável dependente, movemos a discussão para os mecanismos causais. Feitas as considerações relativas à sistemática do Enem/SiSU, ainda assim a nossa aposta é que condições socioeconômicas desfavorecidas tendem a reduzir a probabilidade de aspiração pelo ESP. Entendemos que a associação entre informação incompleta sobre a educação terciária e as formas de acesso a ela, de um lado, e avaliações distintas de benefícios, custos e riscos da transição para esse nível de ensino, de outro, redundem em análises que são próprias de cada condição socioeconômica. Com menos 
informação e escassez de exemplos em seu meio que seguiram esse caminho, estudantes com status socioeconômico mais baixo seriam menos propensos a almejar a educação superior pública, ceteris paribus (primeiro mecanismo causal).

Karruz (2018) discorre sobre potenciais efeitos da LdasC na demanda pelo ensino superior federal; em sua visão, ao atenuar os riscos percebidos, entre eles o de não aprovação nos processos seletivos, a reserva de vagas tenderia a ativar a demanda pelo ensino superior federal entre elegíveis às cotas, tudo o mais constante. Assim, para além de uma melhoria informacional sobre as formas de acesso ao ESP advindas da grande visibilidade alcançada pela LdasC, é plausível esperar que essa política afete a formação de aspirações também pela via da redução dos riscos percebidos pelo público-alvo (segundo mecanismo causal).

Não é conhecido o tempo necessário para que esses efeitos madurem e se façam perceptíveis nas aspirações educacionais. Todavia, é premissa deste trabalho que, no intervalo analisado, de 2012 a 2016, eventuais impactos dessa natureza sejam observáveis. A partir de 2017, o item sobre motivações para prestar o exame não foi incluído no questionário socioeconômico do Enem, o que nos impede de alargar a janela temporal sob escrutínio.

Há, ainda, outro mecanismo a considerar. Apesar de a LdasC ter estabelecido um esquema de cotas e subcotas, em que apenas o segundo nível de subcotas aborda a questão racial, a cobertura midiática dessa e de ações afirmativas anteriores tendeu a representar o estudante beneficiário a partir de uma perspectiva racial (Ferreira, 2019). Também, a maior participação de negros no alunado tende a favorecer a multiplicação de role models ${ }^{11}$ e a fortalecer o senso de pertencimento em relação à ESP. Portanto, o componente racial da lei e da sua divulgação podem ter assim impulsionado o interesse pelo ESP na M1 (terceiro mecanismo causal).

Com base na bibliografia relatada na seção anterior, nos três mecanismos descritos e na observação do contexto brasileiro, são colocadas à prova as seguintes hipóteses:

- H1. Examinados com melhor preparo acadêmico, apurado via nota no Enem, são mais propensos a buscar o ESP.

- H2. Egressos do ensino médio privado, indivíduos com renda per capita superior a 1,5 salário mínimo, brancos e amarelos (em relação a pretos, pardos e indígenas) são mais prováveis de almejarem instituições públicas de ensino superior.

- H3. A LdasC eleva essa aspiração entre examinados no Enem elegíveis à M1 (egressos do ensino médio público, de baixa renda, e pretos, pardos ou indígenas) e deprime essas aspirações entre aqueles disputando vagas em ampla concorrência (M5).

Hipótese $\mathrm{H} 2$ atém-se aos critérios de elegibilidade para M1, pressupondo que o não atendimento de cada um deles se associe com maior probabilidade de aspirar ao ESP. Em H3, a delimitação a apenas duas modalidades de entrada objetiva simplificar a análise, ao mesmo tempo em que chama a atenção para características distintivas de M1 e M5. O primeiro segmento reúne o maior número de condições historicamente desfavorecidas no que tange ao acesso à graduação. Para o segundo, a reserva de vagas implica uma redução do número de assentos disponíveis no ensino superior federal, tudo o mais constante; dessa forma, o tratamento conferido pela ação afirmativa é oposto para M5 em relação à M1 (e às demais modalidades de reserva: M2, M3 e M4).

Possivelmente, os efeitos da LdasC na demanda pelo ESP são diferentes para indivíduos de alto desempenho acadêmico. Em função de sua performance histórica, os candidatos mais bem preparados provavelmente concentram os mais bem informados sobre o ensino superior (estimulados que foram em resposta a bons resultados ao longo da educação básica), e os mais inclinados a considerar o ESP 
uma alternativa a seu alcance, ainda que bastante seletiva. Nesse sentido, é razoável esperar que efeitos da reserva de vagas sobre aspirações sejam mais amenos entre o público potencialmente beneficiário de melhor preparo acadêmico. Em sentido inverso, como as aspirações são mediadas pelo autoconceito acadêmico (Eccles, 2009; Korhonen et al., 2016), o efeito líquido nas aspirações poderia ser mínimo entre candidatos menos preparados. Para analisar eventuais efeitos diferenciais da LdasC de acordo com o preparo acadêmico, o modelo estimado conta com interações entre exposição ao tratamento (combinação de modalidade de entrada e ano) e pertencimento ao decil superior da média das notas obtidas nas cinco provas do Enem. ${ }^{12}$ Não propomos hipóteses direcionais para essas interações.

Tendo em mente os registros de que o gênero medeia a formação de expectativas educacionais (Eccles, 2009; Jacob \& Wilder, 2010; Korhonen et al., 2016), além da estimação para toda a amostra, o modelo empírico será estimado separadamente para as subamostras de homens e mulheres. Dessa forma, é possível analisar se o efeito dos condicionantes (incluindo a LdasC) varia por sexo. ${ }^{13}$

Para esta pesquisa, elegemos o caso da UFMG, uma universidade grande (com mais de 31 mil alunos de graduação, distribuídos em 91 cursos presenciais) e de excelência. Apesar de sua relevância no cenário nacional, a UFMG recruta seus estudantes localmente, sendo que, em 2015, 76\% dos calouros residiam em Belo Horizonte ou em municípios do entorno (Takahashi et al., 2015). Consequentemente, domina o mercado de IES públicas na RMBH, atualmente oferecendo mais de $70 \%$ das vagas nesse segmento. ${ }^{14}$ Essa opção de caso apresenta a vantagem de aproximar o público analisado - examinados no Enem - de sua escolha mais provável de IES pública, aumentando a validade da inferência causal dos impactos da LdasC.

$\mathrm{Na}$ UFMG, a implementação da LdasC seguiu estritamente os percentuais mínimos de reserva. As cotas foram implementadas conforme um padrão escalonado definido pela própria lei: 12,5\%, $25,0 \%, 37,5 \%$ e $50,0 \%$ das vagas de cada curso e turno de IES federais foram destinadas a cotistas nos anos de 2013, 2014, 2015 e 2016, respectivamente. A implantação gradual da LdasC torna a expansão da reserva "como se" aleatória ("as if" random) entre coortes de concluintes do ensino médio com uma certa idade, possibilitando um experimento natural (Dunning, 2008).

Para concluintes do ensino médio em 2012 com 17 anos em 31 de dezembro daquele ano (a idade de maior incidência nesse perfil entre participantes do Enem), prestar o Enem em 2012 e concorrer a uma vaga no ESP federal com início no primeiro semestre de 2013 (quando a reserva de vagas mínima era de 12,5\%), e não no primeiro semestre de 2012 (quando não havia vagas reservadas), é uma condição decorrente do seu ano de nascimento, um evento completamente alheio ao controle do indivíduo e aleatório em natureza. Essa comparabilidade presumida entre as coortes, exceto pela presença ou intensidade do tratamento, é o elemento central da estratégia de identificação dos efeitos da reserva de vagas.

No modelo empírico, a especificação da equação de regressão procurou incorporar o maior número possível de condicionantes das aspirações educacionais mencionados na bibliografia, organizando-os em torno dos cinco agrupamentos enumerados por Jacob e Wilder (2010). Infelizmente, nem todos os fatores listados nos trabalhos de referência podem ser operacionalizados com base nos microdados do Enem - entre os que nos escapam estão autoconceito acadêmico, grau de conhecimento sobre processos seletivos e instituições e presença de roles models que frequentaram o ESP. Outros, como alguns dos fatores escolares (por exemplo, expectativas dos pares, incentivo oferecido por professores), só podem ser aproximados indireta e parcialmente (por exemplo, por meio da dependência administrativa e localização da escola onde o estudante concluiu ou concluirá o ensino médio).

\footnotetext{
12 Ciências da Natureza e suas Tecnologias; Ciências Humanas e suas Tecnologias; Linguagens, Códigos e suas Tecnologias; Matemática e suas Tecnologias; e Redação.

13 No questionário socioeconômico do Enem, não se pergunta sobre gênero, mas apenas sobre sexo. As opções de resposta são somente "Masculino" e "Feminino". Neste trabalho, os termos "gênero" e "sexo" são usados como sinônimos.

14 Cálculo nosso, baseado na consulta a websites das instituições e a editais, realizada em 1 mar. 2020.
} 
Ainda, algumas covariáveis (isto é, variáveis independentes) incluídas no modelo de regressão não foram objeto de estudos prévios, e, para elas, a existência e direção de uma associação com aspirações é completamente incerta. Exemplo disso são as aspirações relacionadas ao ensino superior privado e à obtenção de bolsa de estudos e crédito universitário, fatores que qualificam o investimento - em particular, a apreciação do risco de não admissão no ESP. ${ }^{15}$ Esquematicamente, a equação de regressão é representada como segue:

$$
\ln [p /(1-p)]_{i j t}=\alpha_{j}+\beta X_{i j t}+d_{t}+\varepsilon_{i j t} \text { em que: } p=P\left(y_{i j t}=1\right) ; \alpha_{j}=\gamma+\mu_{j}
$$

A variável dependente $\left(y_{i j t}\right)$ é um indicador binário. O modelo estimado é do tipo logit hierárquico misto, com examinados agrupados ao nível da edição do Enem (efeitos fixos de ano, $d_{t}$ ) e da escola onde o indivíduo está concluindo o ensino médio (interceptos aleatórios, $\left.\alpha_{j}\right) .{ }^{16}$ Esse modelo reconhece a estrutura de geração dos dados: as aspirações pelo ensino superior em cada edição do Enem por estudantes de cada escola são formadas concomitantemente e em um mesmo ambiente. $\mathrm{O}$ modelo separa a variância entre escolas da variância em uma escola, explicitando que as observações de uma mesma escola compartilham parte de sua variância (Agresti, 2007). Preferiu-se a especificação com interceptos aleatórios em vez de efeitos fixos de escola. Isso porque nos interessam atributos das escolas (em particular, dependência administrativa); com efeitos fixos, esses atributos seriam perfeitamente colineares com as dummies indicativas das escolas, o que prejudicaria a estimação dos coeficientes para a rede de ensino frequentada.

Além de variáveis que identificam efeitos da LdasC (detalhadas a seguir), covariáveis $\left(X_{i j t}\right)$ incluem fatores individuais (descritores do desempenho no Enem, cor/raça e gênero), fatores familiares (renda e outros recursos disponíveis no domicílio, escolaridade de pai e mãe), fatores da comunidade (indicadores para município de residência), fatores escolares (dependência administrativa da escola) e fatores do investimento (interesse no ensino superior privado, em bolsa de estudos e no Fies).

A dummy para M1 retrata a diferença inicial (isto é, no Enem 2012) de aspiração pelo ESP entre as modalidades 1 e 5 . As interações entre M1 e ano do Enem $\left(d_{t}\right)$ informam se essa diferença inicial foi alterada nos anos subsequentes (nos quais houve ampliação da reserva, exceto no caso do Enem 2016, considerado no processo seletivo da UFMG para entrada em 2017). O conjunto de interações entre modalidade, ano do Enem e localização no decil superior da nota média das cinco provas reporta se o efeito da $\mathrm{Ldas} C$ para indivíduos elegíveis à $\mathrm{M} 1$ varia conforme o preparo acadêmico dos examinados. Isoladamente, os indicadores de ano do Enem $\left(d_{t}\right)$ retratam variações longitudinais no nível de aspiração dos indivíduos concorrendo na M5. Analogamente, as interações entre ano do Enem e decil superior de nota informam se eventuais efeitos da LdasC no público da M5 diferem de acordo com o preparo acadêmico.

Foram considerados os microdados das edições 2012 a 2016 do Enem, pois essas aplicações são as que contêm a pergunta sobre motivação para prestar o exame, com redação consistente ao longo dos anos. As informações são organizadas como um painel de dados de corte transversal empilhados. Assim, a identificação de efeitos da LdasC conta com comparações entre grupos (M1 e M5) e ao longo do tempo, em uma estrutura analítica assemelhada à do modelo de diferença em diferenças. Aqui, todavia, não há um grupo de comparação que não tenha recebido qualquer tratamento - ao contrário, M5 recebeu o tratamento oposto ao de M1. Portanto, além de captar tendências gerais não exclusivas de M1, M5 é essencial à avaliação de impacto da LdasC. Sob a premissa de simetria de efeito entre grupos, espera-se de M5 uma resposta contrária àquela de M1.

\footnotetext{
15 Por exemplo, para indivíduos com alto interesse em IES privadas, a variação do risco de não admissão decorrente da expansão da reserva de vagas deve ter um menor efeito nas aspirações pelo ESP. Como aquele interesse está concentrado na M1, a omissão de tal controle poderia gerar viés na estimação do impacto das cotas.

16 Estimativas foram calculadas com o auxílio do software Stata, comando "melogit".
} 
Após a imposição de uma série de restrições, ${ }^{17}$ a amostra empregada na análise de regressão inclui 53.018 examinados, todos concluintes do ensino médio e residentes na $\mathrm{RMBH}$, incluindo o chamado Colar Metropolitano, abrangendo 50 municípios. ${ }^{18}$ As observações estão assim distribuídas: 36.993 (69,8\%) elegíveis à M1 e 16.025 (30,2\%) egressos (total ou parcialmente) do ensino médio privado, portanto inelegíveis às vagas reservadas.

\section{Análise}

Médias amostrais ${ }^{19}$ e os resultados das estimações são apresentados na Tabela $1 .{ }^{20}$ Dentre os fatores individuais, destaca-se o desempenho no Enem. Pela especificação (1), que inclui toda a amostra, indivíduos localizados no decil superior de nota apresentam chance ${ }^{21}$ de aspirar ao ESP duas vezes maior que os demais (estes compõem a categoria de referência); examinados nos cinco percentis superiores mostram chance cinco vezes maior que a do grupo de referência, ceteris paribus. ${ }^{22}$ Confirma-se, assim, a primeira hipótese.

\section{TABELA 1}

MÉDIA AMOSTRAL E RAZÕES DE CHANCES ESTIMADAS EM MODELOS DE REGRESSÃO LOGIT PARA A MOTIVAÇÃO DE INGRESSAR NO ESP, COM INTERCEPTOS ALEATÓRIOS POR ESCOLA, MODALIDADES 1 E 5, RESPOSTA 5

\begin{tabular}{|c|c|c|c|c|}
\hline \multirow[b]{3}{*}{ Variável } & \multirow[b]{3}{*}{ Média } & \multicolumn{3}{|c|}{ Resposta: 5} \\
\hline & & (1) & $(2)$ & (3) \\
\hline & & Completo & Homens & Mulheres \\
\hline \multicolumn{5}{|l|}{ Fatores individuais } \\
\hline Nota média no Enem no decil superior do ano & 0,229 & $\begin{array}{c}3,134 * * * \\
(0,407)\end{array}$ & $\begin{array}{c}2,396 * * * \\
(0,443)\end{array}$ & $\begin{array}{c}4,283 * * * \\
(0,899)\end{array}$ \\
\hline Nota média no Enem nos 5 percentis superiores do ano & 0,145 & $\begin{array}{l}1,934 * * * \\
(0,204)\end{array}$ & $\begin{array}{c}2,486 * * * \\
(0,370)\end{array}$ & $\begin{array}{l}1,505 * * * \\
(0,216)\end{array}$ \\
\hline $\begin{array}{l}\text { Alcançou um percentil mais alto em Ciências da Natureza ou } \\
\text { Matemática }\end{array}$ & 0,444 & $\begin{array}{c}0,921 * * * \\
(0,023)\end{array}$ & $\begin{array}{c}0,958 \\
(0,039)\end{array}$ & $\begin{array}{l}0,908 * * * \\
(0,029)\end{array}$ \\
\hline Optou por espanhol como língua estrangueira & 0,408 & $\begin{array}{c}0,960 \\
(0,025)\end{array}$ & $\begin{array}{c}0,959 \\
(0,042)\end{array}$ & $\begin{array}{c}0,956 \\
(0,033)\end{array}$ \\
\hline Preto & 0,191 & $\begin{array}{l}1,138 * \\
(0,087)\end{array}$ & $\begin{array}{c}1,142 \\
(0,129)\end{array}$ & $\begin{array}{c}1,142 \\
(0,112)\end{array}$ \\
\hline Pardo & 0,622 & $\begin{array}{c}1,096 \\
(0,082)\end{array}$ & $\begin{array}{c}1,159 \\
(0,123)\end{array}$ & $\begin{array}{c}1,058 \\
(0,102)\end{array}$ \\
\hline Indígena & 0,008 & $\begin{array}{l}0,781 * \\
(0,106)\end{array}$ & $\begin{array}{c}0,699 \\
(0,157)\end{array}$ & $\begin{array}{c}0,815 \\
(0,143)\end{array}$ \\
\hline Masculino & 0,367 & $\begin{array}{c}0,860 * * * \\
(0,023)\end{array}$ & & \\
\hline
\end{tabular}

17 Os requisitos para inclusão na amostra foram os seguintes: obter nota maior que zero na redação e ter nota para as demais provas do Enem; dispor de informação para os critérios de elegibilidade às cotas; ser concluinte do ensino médio no ano em que prestou o Enem; ter 17 anos completos em 31 de dezembro do ano em que prestou Enem; ser solteiro, não ser gestante ou lactante, nem apresentar necessidade especial (por exemplo, em função de baixa visão ou déficit de atenção); ter número de inscrição único; ser residente da RMBH; não apresentar inconsistência ou indeterminação na informação sobre elegibilidade às cotas; dispor de informação para todas as variáveis incluídas no modelo de regressão.

18 Observações por ano: 2012: 11.922; 2013: 12.669; 2014: 4.163; 2015: 12.469; 2016: 11.795. Valores faltantes para a dependência administrativa do ensino médio levaram a uma redução considerável da subamostra de 2014.

19 Note-se que a proporção de indivíduos no decil superior e nos cinco percentis superiores de notas no Enem excede 10 e $5 \%$ da amostra, respectivamente. Esses percentis foram calculados antes da imposição de restrições à amostra. A distribuição original de notas é assimétrica, com média maior que a mediana, e com muitas observações de mesmo valor.

$20 \mathrm{Na}$ Tabela 1, a operacionalização de aspiração considera apenas respostas 5. As mesmas especificações, porém calculadas com base em uma definição ligeiramente diferente de aspiração, contemplando respostas 4 ou 5, mostram efeitos da LdasC mais amenos na M1 e não detectáveis na M5. Esses resultados não são mostrados, mas estão disponíveis sob demanda.

21 Chance corresponde à probabilidade de o evento ocorrer (neste caso, o indivíduo almejar o ESP) dividida pela probabilidade de o evento não ocorrer (ou seja, 1 menos o numerador). A razão de chances é obtida ao se elevar o número neperiano (e) ao coeficiente estimado do modelo logit.

22 A dummy que identifica pertencimento aos cinco percentis superiores de nota caracteriza uma interação, pois todos os indivíduos com valor 1 para essa covariável também assumem valor 1 para o indicador de pertencimento ao decil superior de notas. Em modelos logit, a interpretação de coeficientes de interação implica um efeito multiplicativo na razão de chances das variáveis em nível. 


\begin{tabular}{|c|c|c|c|c|}
\hline \multirow[b]{3}{*}{ Variável } & \multirow[b]{3}{*}{ Média } & \multicolumn{3}{|c|}{ Resposta: 5} \\
\hline & & (1) & (2) & (3) \\
\hline & & Completo & Homens & Mulheres \\
\hline \multicolumn{5}{|l|}{ Fatores familiares } \\
\hline Renda familiar per capita até 1,5 salário mínimo & 0,837 & $\begin{array}{c}1,047 \\
(0,077)\end{array}$ & $\begin{array}{c}0,979 \\
(0,101)\end{array}$ & $\begin{array}{c}1,099 \\
(0,110)\end{array}$ \\
\hline Renda familiar até 1 salário mínimo (inclusive) & 0,114 & $\begin{array}{c}0,647 * * * \\
(0,034)\end{array}$ & $\begin{array}{c}0,689 * * * \\
(0,060)\end{array}$ & $\begin{array}{c}0,600 * * * \\
(0,038)\end{array}$ \\
\hline Renda familiar entre 1 (exclusive) e 2 salários mínimos (inclusive) & 0,357 & $\begin{array}{c}0,777 * * * \\
(0,032)\end{array}$ & $\begin{array}{c}0,851 * * \\
(0,057)\end{array}$ & $\begin{array}{c}0,709 * * * \\
(0,038)\end{array}$ \\
\hline Renda familiar entre 2 (exclusive) e 3 salários mínimos (inclusive) & 0,197 & $\begin{array}{c}0,865^{* * *} \\
(0,037)\end{array}$ & $\begin{array}{c}0,903 \\
(0,063)\end{array}$ & $\begin{array}{c}0,816 * * * \\
(0,045)\end{array}$ \\
\hline Número de pessoas morando em casa & 4,158 & $\begin{array}{c}0,968 * * * \\
(0,009)\end{array}$ & $\begin{array}{c}0,996 \\
(0,016)\end{array}$ & $\begin{array}{c}0,952 * * * \\
(0,011)\end{array}$ \\
\hline Internet em casa & 0,819 & $\begin{array}{c}0,894 * * * \\
(0,033)\end{array}$ & $\begin{array}{c}0,926 \\
(0,061)\end{array}$ & $\begin{array}{c}0,875 * * * \\
(0,039)\end{array}$ \\
\hline Computador em casa & 0,839 & $\begin{array}{c}1,004 \\
(0,037)\end{array}$ & $\begin{array}{l}0,894 * \\
(0,058)\end{array}$ & $\begin{array}{c}1,058 \\
(0,049)\end{array}$ \\
\hline Exerce ou já exerceu atividade remunerada & 0,333 & $\begin{array}{c}0,961 \\
(0,030)\end{array}$ & $\begin{array}{c}0,927 \\
(0,045)\end{array}$ & $\begin{array}{c}0,970 \\
(0,037)\end{array}$ \\
\hline Mãe com ensino superior completo & 0,212 & $\begin{array}{c}1,275^{* * *} \\
(0,058)\end{array}$ & $\begin{array}{c}1,326 * * * \\
(0,091)\end{array}$ & $\begin{array}{c}1,252 * * * \\
(0,073)\end{array}$ \\
\hline Pai com ensino superior completo & 0,165 & $\begin{array}{c}1,286 * * * \\
(0,069)\end{array}$ & $\begin{array}{c}1,306 * * * \\
(0,103)\end{array}$ & $\begin{array}{c}1,279 * * * \\
(0,092)\end{array}$ \\
\hline \multicolumn{5}{|l|}{ Fatores da comunidade } \\
\hline Reside em Belo Horizonte & 0,424 & $\begin{array}{c}1,305^{* * *} \\
(0,048)\end{array}$ & $\begin{array}{c}1,361 * * * \\
(0,074)\end{array}$ & $\begin{array}{c}1,308 * * * \\
(0,056)\end{array}$ \\
\hline Reside em Betim & 0,080 & $\begin{array}{c}0,964 \\
(0,055)\end{array}$ & $\begin{array}{c}0,897 \\
(0,074)\end{array}$ & $\begin{array}{c}1,015 \\
(0,074)\end{array}$ \\
\hline Reside em Contagem & 0,114 & $\begin{array}{c}1,092 \\
(0,059)\end{array}$ & $\begin{array}{c}1,106 \\
(0,085)\end{array}$ & $\begin{array}{c}1,100 \\
(0,073)\end{array}$ \\
\hline \multicolumn{5}{|l|}{ Fatores escolares } \\
\hline Concluiu ou concluirá o ensino médio em escola federal & 0,009 & $\begin{array}{c}4,561 * * * \\
(1,744)\end{array}$ & $\begin{array}{c}3,685^{* * *} \\
(1,572)\end{array}$ & $\begin{array}{c}5,898 * * * \\
(2,189)\end{array}$ \\
\hline Concluiu ou concluirá o ensino médio em escola municipal & 0,017 & $\begin{array}{c}1,381 * * * \\
(0,156)\end{array}$ & $\begin{array}{c}1,375^{*} \\
(0,230)\end{array}$ & $\begin{array}{c}1,382 * * \\
(0,181)\end{array}$ \\
\hline Concluiu ou concluirá o ensino médio em escola privada & 0,282 & $\begin{array}{c}1,710 * * * \\
(0,177) \\
\end{array}$ & $\begin{array}{c}1,585^{* * *} \\
(0,257)\end{array}$ & $\begin{array}{c}1,624 * * * \\
(0,215)\end{array}$ \\
\hline \multicolumn{5}{|l|}{ Fatores do investimento (inclusive LdasC) } \\
\hline Prestou Enem para ingressar na educação superior privada (5) & 0,430 & $\begin{array}{c}1,954 * * * \\
(0,066)\end{array}$ & $\begin{array}{c}2,399 * * * \\
(0,134)\end{array}$ & $\begin{array}{c}1,727 * * * \\
(0,067)\end{array}$ \\
\hline $\begin{array}{l}\text { Prestou Enem para conseguir uma bolsa de estudos (ProUni, } \\
\text { outras) (5) }\end{array}$ & 0,742 & $\begin{array}{c}2,151 * * * \\
(0,084)\end{array}$ & $\begin{array}{l}2,242 * * * \\
(0,133)\end{array}$ & $\begin{array}{l}2,054 * * * \\
(0,098)\end{array}$ \\
\hline $\begin{array}{l}\text { Prestou Enem para participar do Programa de Financiamento } \\
\text { Estudantil - FIES (5) }\end{array}$ & 0,514 & $\begin{array}{c}1,494 * * * \\
(0,046)\end{array}$ & $\begin{array}{c}1,590 * * * \\
(0,080)\end{array}$ & $\begin{array}{l}1,448 * * * \\
(0,052)\end{array}$ \\
\hline Modalidade 1 & 0,698 & $\begin{array}{l}0,675 * * * \\
(0,087)\end{array}$ & $\begin{array}{l}0,505 * * * \\
(0,104)\end{array}$ & $\begin{array}{c}0,792 \\
(0,128)\end{array}$ \\
\hline Modalidade 1 no Enem 2013 & 0,164 & $\begin{array}{c}1,186 \\
(0,139)\end{array}$ & $\begin{array}{l}1,265 \\
(0,241)\end{array}$ & $\begin{array}{c}1,152 \\
(0,171)\end{array}$ \\
\hline Modalidade 1 no Enem 2014 & 0,067 & $\begin{array}{c}1,359 \\
(0,266)\end{array}$ & $\begin{array}{c}2,332 * \star * \\
(0,567)\end{array}$ & $\begin{array}{c}0,832 \\
(0,257)\end{array}$ \\
\hline Modalidade 1 no Enem 2015 & 0,162 & $\begin{array}{c}1,318 * * \\
(0,161)\end{array}$ & $\begin{array}{c}2,167 * * * \\
(0,425)\end{array}$ & $\begin{array}{c}0,950 \\
(0,142)\end{array}$ \\
\hline Modalidade 1 no Enem 2016 & 0,153 & $\begin{array}{c}1,072 \\
(0,127)\end{array}$ & $\begin{array}{c}1,432 * \\
(0,284)\end{array}$ & $\begin{array}{c}0,877 \\
(0,139)\end{array}$ \\
\hline Enem 2013 & 0,239 & $\begin{array}{c}0,879 \\
(0,095)\end{array}$ & $\begin{array}{c}0,854 \\
(0,148)\end{array}$ & $\begin{array}{c}0,886 \\
(0,125)\end{array}$ \\
\hline Enem 2014 & 0,079 & $\begin{array}{c}0,798 \\
(0,153)\end{array}$ & $\begin{array}{c}0,555^{\star *} \\
(0,130)\end{array}$ & $\begin{array}{c}1,157 \\
(0,351)\end{array}$ \\
\hline
\end{tabular}




\begin{tabular}{|c|c|c|c|c|}
\hline \multirow[b]{3}{*}{ Variável } & \multirow[b]{3}{*}{ Média } & \multicolumn{3}{|c|}{ Resposta: 5} \\
\hline & & (1) & $(2)$ & (3) \\
\hline & & Completo & Homens & Mulheres \\
\hline \multicolumn{5}{|l|}{ Fatores do investimento (inclusive LdasC) } \\
\hline Enem 2015 & 0,235 & $\begin{array}{l}0,799 * * \\
(0,091)\end{array}$ & $\begin{array}{l}0,580 * * * \\
(0,105)\end{array}$ & $\begin{array}{c}1,013 \\
(0,141)\end{array}$ \\
\hline Enem 2016 & 0,222 & $\begin{array}{l}0,954 \\
(0,106)\end{array}$ & $\begin{array}{l}0,728 * \\
(0,135)\end{array}$ & $\begin{array}{l}1,155 \\
(0,174)\end{array}$ \\
\hline $\begin{array}{l}\text { Modalidade } 1 \text { no Enem } 2013 \text { com nota média no decil superior } \\
\text { daquele ano }\end{array}$ & 0,011 & $\begin{array}{c}1,174 \\
(0,284)\end{array}$ & $\begin{array}{l}1,200 \\
(0,422)\end{array}$ & $\begin{array}{c}1,212 \\
(0,421)\end{array}$ \\
\hline $\begin{array}{l}\text { Modalidade } 1 \text { no Enem } 2014 \text { com nota média no decil superior } \\
\text { daquele ano }\end{array}$ & 0,004 & $\begin{array}{l}1,628 \\
(0,784)\end{array}$ & $\begin{array}{c}1,172 \\
(0,694)\end{array}$ & $\begin{array}{c}2,106 \\
(1,657)\end{array}$ \\
\hline $\begin{array}{l}\text { Modalidade } 1 \text { no Enem } 2015 \text { com nota média no decil superior } \\
\text { daquele ano }\end{array}$ & 0,011 & $\begin{array}{l}1,343 \\
(0,296)\end{array}$ & $\begin{array}{c}0,857 \\
(0,258)\end{array}$ & $\begin{array}{c}2,090 * * \\
(0,679)\end{array}$ \\
\hline $\begin{array}{l}\text { Modalidade } 1 \text { no Enem } 2016 \text { com nota média no decil superior } \\
\text { daquele ano }\end{array}$ & 0,012 & $\begin{array}{c}1,331 \\
(0,301)\end{array}$ & $\begin{array}{l}1,381 \\
(0,451)\end{array}$ & $\begin{array}{l}1,315 \\
(0,431)\end{array}$ \\
\hline Enem 2013 com nota média no decil superior daquele ano & 0,055 & $\begin{array}{c}1,021 \\
(0,177)\end{array}$ & $\begin{array}{l}0,985 \\
(0,252)\end{array}$ & $\begin{array}{l}1,029 \\
(0,280)\end{array}$ \\
\hline Enem 2014 com nota média no decil superior daquele ano & 0,009 & $\begin{array}{l}0,867 \\
(0,300)\end{array}$ & $\begin{array}{c}1,111 \\
(0,462)\end{array}$ & $\begin{array}{c}0,711 \\
(0,419)\end{array}$ \\
\hline Enem 2015 com nota média no decil superior daquele ano & 0,057 & $\begin{array}{l}0,736 * \\
(0,134)\end{array}$ & $\begin{array}{c}1,036 \\
(0,269)\end{array}$ & $\begin{array}{c}0,541 * * \\
(0,138)\end{array}$ \\
\hline Enem 2016 com nota média no decil superior daquele ano & 0,056 & $\begin{array}{c}0,785 \\
(0,136) \\
\end{array}$ & $\begin{array}{c}0,831 \\
(0,206)\end{array}$ & $\begin{array}{c}0,768 \\
(0,205)\end{array}$ \\
\hline Constante & & $\begin{array}{c}2,312 * * * \\
(0,335)\end{array}$ & $\begin{array}{c}2,036 * * * \\
(0,478)\end{array}$ & $\begin{array}{c}2,477 * * * \\
(0,478)\end{array}$ \\
\hline Estimativa do desvio padrão do intercepto (em escala logit) & & 0,273 & 0,260 & 0,272 \\
\hline Número de grupos (escolas) & & 1,347 & 955 & 1,131 \\
\hline Observações & & 53,018 & 19,478 & 33,540 \\
\hline
\end{tabular}

Fonte: Elaboração própria, com base nos microdados do Enem (2012-2016).

Notas: Erros padrão robustos, agrupados por escola, mostrados em parênteses. $* \star * p<0,01 ; * * p<0,05 ; * p<0,10$. Todos os modelos foram calculados com 30 pontos de integração, utilizando-se a quadratura Gauss-Hermite adaptativa (com atualização via média e desvio padrão) como método de integração.

Examinados com desempenho relativamente superior em Ciências da Natureza ou Matemática tendem a estar menos motivados a ingressar no ESP. Uma possível explicação, não testável com os dados disponíveis, é que esses indivíduos estejam interessados em cursos com maior retorno financeiro, de sorte que o investimento no ensino superior privado lhes seja mais vantajoso que para candidatos a outros cursos.

Notadamente, homens correspondem a bem menos da metade da amostra (19.478 observações, ou 36,7\%). Essa sub-representação é sugestiva de alguma autosseleção, na medida em que os homens que prestam Enem tendem a estar mais bem preparados academicamente que os demais. Mesmo assim, o modelo indica uma desigualdade entre sexos: em média, homens mostram chance aproximadamente $14,0 \%$ menor de aspirar ao ESP.

Controlando-se pelas demais covariáveis, os outros fatores individuais não parecem influir nas aspirações pelo ESP. A opção por espanhol como língua estrangeira, que poderia ser interpretada como um indicador de preparo acadêmico mais frágil - na medida em que evita a alternativa, o inglês, idioma de menor semelhança com o português, não mostra significância, apesar de as estimativas sinalizarem uma relação negativa com a variável dependente (razão de chances menor que a unidade). Similarmente, os coeficientes de cor/raça não são estatisticamente diferentes de 0 , ainda que pareça haver maior aspiração pelo ESP entre pretos e pardos e menor entre indígenas, em relação a brancos e amarelos, tudo o mais constante.

Quanto aos fatores familiares, a renda familiar (total) e o número de moradores no domicílio revelam relação positiva e negativa com a aspiração ao ESP, como esperado. Indivíduos com renda 
familiar até um salário mínimo, que constituem 11,4\% da amostra, possuem chance 35,3\% menor de aspirar ao ESP que jovens com renda familiar superior a três salários mínimos (categoria de referência). $\mathrm{O}$ critério de renda da LdasC não mostrou relação com a variável dependente. Uma potencial razão para tal resultado, além da redundância com variáveis afins, é que esse limiar de renda é muito alto, tornando-se pouco discriminante; de fato, na amostra, 83,7\% dos examinados e 99,5\% (não mostrado) dos egressos do ensino médio público enquadram-se nesse quesito.

Quando estatisticamente significantes, os parâmetros para acesso à internet em casa sugerem uma associação negativa com aspirações, contrariando a expectativa. Já a escolaridade dos pais correlaciona-se positivamente com as aspirações dos filhos, como esperado. Filhos de mãe com ensino superior completo têm chance cerca de 30\% maior de almejarem o ESP. O efeito se repete para filhos de pai com educação terciária.

Em comparação com outros municípios da região metropolitana, a chance de moradores de Belo Horizonte aspirarem à universidade pública é 30,5\% maior. No que concerne aos fatores escolares, os achados confirmam a expectativa de que a dependência administrativa da escola onde o jovem conclui o ensino médio importa para a formação de aspirações. Egressos do ensino médio federal (0,9\% da amostra) apresentam chance 3,5 vezes maior de aspirar ao ESP que suas contrapartes da rede estadual (grupo de referência, 69,2\% da amostra). Essa propensão é bastante mais alta que a de egressos da rede privada (28,2\% da amostra): estes possuem chance $71 \%$ mais alta de ambicionar o ESP que egressos da rede estadual. Tal evidência está alinhada com $\mathrm{H} 2$, na medida em que estudantes da rede privada são mais predispostos a aspirar ao ESP que os da maior parte da rede pública (estadual). Ao mesmo tempo, transparece enorme desigualdade na rede pública: egressos de escolas federais são muito mais propensos a pretender o ESP que os de escolas estaduais.

Sobre os fatores de investimento, interesse no ensino superior privado, em bolsas de estudo e no Fies, associa-se positivamente à aspiração pelo ESP. Possivelmente, todas essas variáveis revelam um alto valor intrínseco atribuído ao ensino superior. Dessa forma, sobressai o que esses itens do questionário têm em comum, em detrimento do caráter substitutivo de uma via de acesso em relação às outras.

Finalmente, resta analisar as variáveis referentes à reserva de vagas. Enquanto os coeficientes individuais de renda per capita e cor/raça não são estatisticamente significantes, o atendimento dos três critérios de elegibilidade para a M1 parece deprimir a demanda pelo ESP. Essa condição reduz a razão de chances de esses jovens aspirarem ao ESP. Portanto, tomados em conjunto, os achados amparam parcialmente $\mathrm{H} 2$.

A LdasC parece ter reduzido a diferença de propensões entre M1 e M5, todavia, de maneira diferente para homens e mulheres. $\mathrm{Na}$ especificação completa (1), as razões de chances são maiores que a unidade para as interações entre M1 e ano do Enem, porém estatisticamente significantes apenas no Enem 2015 (ingresso em 2016, quando a reserva de vagas na UFMG atingiu 50\%). Já as especificações por sexo revelam um padrão de comportamento diferencial: enquanto os coeficientes das mulheres não são estatisticamente significantes nem positivos na maior parte dos casos, os coeficientes dos homens são positivos e significantes para as edições 2014 e 2015 do Enem. Na M1, homens com preparo acadêmico variado parecem ter elevado sua aspiração pelo ESP, ao passo que apenas as mulheres no decil superior de notas demonstram a mesma reação - e essa reação é estatisticamente significante somente no Enem 2015.

Analogamente, na M5, identifica-se um declínio da aspiração pelo ESP entre os homens nas edições 2014 e 2015 do Enem. Nesse grupo, também somente as mulheres de alto preparo acadêmico parecem ser afetadas pela restrição de vagas, com sua razão de chances em 2015 diminuída a quase metade daquela de 2012.

Portanto, a evidência sustenta $\mathrm{H} 3$, a qual postula uma elevação da aspiração pelo ESP entre elegíveis à M1 em relação àqueles disputando vagas em M5. Ao mesmo tempo, indica haver efeitos diferenciais, por sexo e ao longo do tempo. Sexo parece ser um fator de moderação na formação de aspirações, já que os efeitos alcançam homens com variados graus de preparo acadêmico, ao passo 
que somente mulheres no decil superior de notas (ou seja, aquelas mais prováveis de terem seu acesso ao ensino superior efetivamente afetado pela reserva de vagas) mostram a mesma resposta à LdasC. Algumas possíveis causas para esse efeito diferencial seriam: a) a tendência de jovens estudantes mulheres atualizarem menos frequentemente que os homens suas expectativas educacionais (Jacob \& Wilder, 2010); e b) uma eventual vantagem informacional em favor das mulheres, o que faria com que apenas aquelas na margem de serem admitidas ou recusadas no ESP esbocem reação à LdasC.

Importante ressaltar, os coeficientes estatisticamente significantes referem-se apenas às edições 2014 e 2015 do Enem; a edição 2016 (com ingresso em 2017; portanto, após a plena implementação das cotas na UFMG) retorna parâmetros na direção esperada, porém não estatisticamente diferentes de zero a 5\% de significância, sugerindo níveis de aspiração semelhantes aos de 2012. Esses resultados indicam que os efeitos da $\mathrm{Ldas} C$ nas aspirações de jovens demoraram pelo menos um ano para se fazerem detectáveis e que sofreram alguma dissipação após a finalização da implementação; infelizmente, a supressão, desde o Enem 2017, da pergunta sobre aspirações impede-nos de explorar essa interpretação.

\section{Conclusões}

Este artigo propôs-se a examinar desigualdades socioeconômicas e raciais nas aspirações pelo ESP entre jovens concluintes do ensino médio e a avaliar se o esquema de reserva de vagas instituído pela LdasC alterou essas aspirações. Para tanto, focamos no caso da UFMG, uma universidade de projeção nacional e excelência, mas que capta a maior parte de seus estudantes localmente, dominando o mercado de IES públicas na RMBH.

O tema das aspirações pelo ensino superior é pouco explorado no contexto brasileiro. Com base em adaptações de trabalhos da literatura internacional das áreas de Psicologia, Sociologia e Economia da Educação, desenvolveu-se um modelo para teste empírico. Ele pressupõe que a formação de aspirações quanto ao ensino superior é sensível a uma variedade de fatores, de natureza individual (por exemplo, desempenho acadêmico), familiar (por exemplo, renda, escolaridade parental), da comunidade (município de residência), da escola (dependência administrativa) e do investimento (por exemplo, riscos associados a diferentes alternativas de IES). Nosso argumento é que a LdasC altera a percepção do risco de não admissão: reduzindo-o para a modalidade de entrada M1 (pretos, pardos e indígenas de baixa renda egressos do ensino médio público) e o elevando para M5 (ampla concorrência).

Três hipóteses foram escrutinadas, postulando as seguintes associações: examinados de melhor preparo acadêmico são mais prováveis de almejar o ESP (H1); os critérios de elegibilidade à M1 associam-se com menor probabilidade de possuir tal ambição (H2); e a LdasC tende a elevar essa aspiração entre examinados no Enem elegíveis à M1, concomitantemente deprimindo essa aspiração entre aqueles disputando vagas na M5 (H3).

A identificação de efeitos da LdasC baseou-se na característica "como se" aleatória da expansão da reserva de vagas, considerando concluintes do ensino médio de uma certa idade (17 anos) no ano em que prestaram Enem. Caracterizou-se, assim, um experimento natural.

Para estimar o modelo empírico, empregou-se análise de regressão logit com efeitos fixos de ano e interceptos aleatórios por escola de conclusão do ensino médio, aplicada aos microdados de cinco edições do Enem (2012 a 2016). A variável dependente corresponde à resposta de examinados sobre a importância de ingresso no ESP como motivação para participar do exame. A amostra compreende mais de 53 mil indivíduos, todos concluintes do ensino médio e residentes da RMBH.

Resultados emprestam suporte às três hipóteses testadas. Indivíduos no decil superior da nota média obtida no Enem apresentam chance duas vezes maior que os posicionados abaixo desse limiar (grupo de referência); pertencentes aos cinco percentis superiores de nota possuem chance cinco vezes maior que o grupo de referência. Corrobora-se, assim, H1. 
A confirmação de $\mathrm{H} 2$, por sua vez, apresenta algumas particularidades. Para indivíduos elegíveis à M1 (isto é, que atendem aos três requisitos), a chance de aspirar ao ESP é inferior à dos egressos do ensino médio privado (M5). Contudo, isoladamente, apenas o critério de dependência administrativa do ensino médio associa-se à aspiração ao ESP. Aqui, destacamos dois resultados. Primeiro, enquanto os egressos da rede privada apresentam chance $70 \%$ maior de declarar essa aspiração que os egressos da rede estadual, os egressos da rede federal possuem chance $356 \%$ maior - ou seja, sua inclinação a perseguir IES públicas é largamente superior à de estudantes das escolas estaduais e das particulares. Segundo, enquanto o critério de renda familiar per capita não mostra associação significativa às aspirações, outras medições de renda familiar o fazem. Isso sugere que o limiar de renda da LdasC seja muito alto e pouco discriminante. Também aponta a existência de um comportamento do tipo income-typical, com indivíduos de baixa renda sendo menos prováveis de ambicionar o ESP, ceteris paribus. Com os dados disponíveis, não é possível sondar as causas desse comportamento, sendo as mais prováveis uma possível deficiência informacional e fatores sociais e culturais que atenuem a percepção do retorno esperado do ESP para pessoas de menor renda. De qualquer forma, considerando que todos os indivíduos observados fizeram as cinco provas do Enem, e tendo em mente a simplificação e o barateamento da application trazidos pelo SiSU, é notável que um comportamento income-typical ainda seja detectável.

A hipótese sobre a LdasC (H3) também encontra amparo na evidência, ao mesmo tempo que levanta questionamentos interessantes. Sexo parece moderar os efeitos da LdasC sobre as aspirações de jovens. Entre os elegíveis à M1, homens de diferentes níveis de preparo acadêmico exibiram aumento na propensão a buscar IES públicas, ao passo que apenas as mulheres de alto desempenho acadêmico reagiram dessa forma à expansão da reserva de vagas. Analogamente, na ampla concorrência as aspirações dehomens (em geral) parecem ter refreado, entretanto somente mulheres de alto desempenho demonstram essa mudança.

Ainda sobre as hipóteses, cabem dois apontamentos. Primeiro, a alta validade interna propiciada pelo experimento natural ampara exclusivamente o teste de $\mathrm{H} 3$, já que a estratégia de identificação se sustenta na comparabilidade presumida entre coortes que enfrentam níveis diferentes de reserva de vaga. Assim, os achados sobre $\mathrm{H} 3$ podem ser considerados causais; aqueles sobre $\mathrm{H} 1$ e $\mathrm{H} 2$ não gozam da mesma prerrogativa. Segundo, sobre H3, os coeficientes estatisticamente significantes referem-se às edições 2014 e 2015 do Enem; a edição 2016 (com ingresso em 2017, portanto após a plena implementação das cotas na UFMG) retorna parâmetros na direção esperada, porém não estatisticamente diferentes de 0 (a 5\% de significância), sugerindo níveis de aspiração semelhantes aos de 2012. Isso pode indicar que os efeitos da LdasC nas aspirações de jovens sofreram alguma dissipação após a finalização da implementação. Infelizmente, a supressão (desde o Enem 2017) da pergunta sobre aspirações impede-nos de explorar essa interpretação.

\section{Agradecimentos}

As autoras agradecem o apoio do Programa Institucional de Auxílio à Pesquisa de Docentes Recém-Contratados, da Pró-Reitoria de Pesquisa da Universidade Federal de Minas Gerais (UFMG).

\section{Referências}

Agresti, A. (2007). An introduction to categorical data analysis (2a. ed.). Wiley-Interscience.

Bermúdez, A. C. (2019, maio 28). Enem 2019: 1 milhão não paga taxa e inscrições alcançam menor no desde 2012. UOL Educação. https://educacao.uol.com.br/noticias/2019/05/28/enem-2019-1-milhao-naopaga-taxa-e-inscricoes-alcancam-menor-n-desde-2012.htm 
Bourdieu, P. (2007). Futuro de classe e causalidade do provável. In M. A. Nogueira \& A. Catani (Orgs.), Escritos de educação (pp. 81-125). Vozes. $1^{a}$ edição de 1974.

Civil Rights Act. Public Law 88-352, 78 STAT 241. (1964, July 02). An Act to enforce the constitutional right to vote, to confer jurisdiction upon the district courts of the United States to provide injunctive relief against discrimination in public accommodations, to authorize the Attorney General to institute suits to protect constitutional rights in public facilities and public education, to extend the Commission on Civil Rights, to prevent discrimination in federally assisted programs, to establish a Commission on Equal Employment Opportunity, and for other purposes. Washington, DC. https://catalog.archives.gov/id/299891

Coleman, J. S., Campbell, E. Q., Hobson, C. J., McPartland, J., Mood, A. M., Weinfeld, F. D., \& York, R. L. (1966). Equality of educational opportunity. Washington: U.S. Department of Health, Education, and Welfare, Office of Education.

Dunning, T. (2008, June). Improving causal inference: Strengths and limitations of natural experiments. Political Research 2uarterly, 61(2), 282-293.

Eccles, J. (2009). Who am I and what am I going to do with my life? Personal and collective identities as motivators of action. Educational Psychologist, 44(2), 78-89.

Emerging economies university rankings 2020. (2020) S.l.: Times Higher Education. https://www. timeshighereducation.com/world-university-rankings/2020/emerging-economies-universityrankings\#!/page/0/length/25/sort_by/rank/sort_order/asc/cols/stats

Ferreira, N. T. (2019, janeiro-março). Ações afirmativas raciais e a atuação do jornal Folha de S.Paulo. Cadernos de Pesquisa, 49(171), 110-128.

Grimm, P. (2011). Social desirability bias. In J. N. Sheth, \& N. K. Malhotra (Orgs.), Wiley International Encyclopedia of Marketing. https://onlinelibrary.wiley.com/doi/abs/10.1002/9781444316568.wiem02057

Hoxby, C. M., \& Avery, C. (2013, Spring). The missing "one-offs": The hidden supply of high-achieving, low-income students. Brookings Papers on Economic Activity, 1-46.

Hoxby, C., \& Turner, S. (2013). Expanding college opportunities for high-achieving, low-income students. Stanford Institute for Economic Policy Research Discussion Paper, 12-14, 1-55.

Instituto Nacional de Estudos e Pesquisas Educacionais Anísio Teixeira. (2019). Sinopse estatística da educação superior 2018. Brasília: Ministério da Educação/Inep. http://inep.gov.br/sinopses-estatisticas-da-educacao-superior.

Jacob, B. A., \& Wilder, T. (2010, January). Educational expectations and attainment. National Bureau of Economic Research Working Paper Series, Cambridge, 15683, 1-58.

Karruz, A. (2018, abril/junho). Oferta, demanda e nota de corte: Experimento natural sobre efeitos da Lei das Cotas no acesso à Universidade Federal de Minas Gerais. Dados, 61(2), 405-462.

Korhonen, J., Tapola, A., Linnanmäki, K., \& Aunio, P. (2016, December). Gendered pathways to educational aspirations: The role of academic self-concept, school burnout, achievement and interest in mathematics and reading. Learning and Instruction, 46, 21-33.

Lei Federal n. 12.711, de 29 de agosto de 2012. Dispõe sobre o ingresso nas universidades federais e nas instituições federais de ensino técnico de nível médio e dá outras providências. Brasília, DF. http:// www.planalto.gov.br/ccivil_03/_ato2011-2014/2012/lei/112711.htm

Lei Federal n. 13.409, de 28 de dezembro de 2016. Altera a Lei n. 12.711, de 29 de agosto de 2012, para dispor sobre a reserva de vagas para pessoas com deficiência nos cursos técnico de nível médio e superior das instituições federais de ensino. Brasília, DF. http://www.planalto.gov.br/ccivil_03/_ato20152018/2016/lei/113409.htm

Machado, C., \& Szerman, C. (2016, September). Centralized admissions and the student-college match. IZA Discussion Paper Series, 10251, 1-49.

Maia, F. de P. G. H. (2019). Realização do ENEM por alunos de escolas públicas: Um estudo sobre burocracia implementadora emescolas estaduais de Belo Horizonte [Trabalho de Conclusão de Curso]. Universidade Federal de Minas Gerais. http://www.fafich.ufmg.br/gestaopublica/wp-content/uploads/2020/05/ FLORA-DE-PAULA-GON\%C3\%87ALVES-HOLANDA-MAIA.pdf 
Nogueira, C. M. M. et al. (2017). Promessas e limites: O SiSU e sua implementação na Universidade Federal de Minas Gerais. Educação em Revista, 33(2), 61-90.

Oreopoulos, P., \& Dunn, R. (2013, January). Information and college access: Evidence from a randomized field experiment. The Scandinavian Journal of Economics, 115(1), 3-26.

Schneider, B., \& Saw, G. (2016, September). Racial and ethnic gaps in postsecondary aspirations and enrollment. The Russell Sage Foundation Journal of the Social Sciences, 2(5), 58-82.

Soares, J. F., \& Júdice, R. (2003, julho/dezembro). A auto-exclusão dos alunos das escolas públicas estaduais de Belo Horizonte no vestibular da UFMG. Ensaio Pesquisa em Educação em Ciências, 5(2), 92-99.

Takahashi, R. H. C., Caminhas, W. M., \& Pena, C. S. (2015). Mudanças no ensino de graduação da UFMG: Análise e perspectivas. Belo Horizonte: Universidade Federal de Minas Gerais. https://www.ufmg.br/ prograd/arquivos/acontece/ApEst.pdf

Valente, R. R., \& Berry, B. J. L. (2017, July). Performance of students admitted through affirmative action in Brazil. Latin American Research Review, 52(1), 18-34.

Wainer, J., \& Melguizo, T. (2018). Políticas de inclusão no ensino superior: Avaliação do desempenho dos alunos baseado no Enade de 2012 a 2014. Educação e Pesquisa, 44, Artigo e162807.

61,5\% dos inscritos no Enem são isentos de taxa. (2012, junho 18). Estadão.edu. https://educacao.estadao.com. $\mathrm{br} /$ noticias/geral,61-5-dos-inscritos-no-enem-sao-isentos-de-taxa, 888033

\section{Nota sobre autoria}

As autoras participaram igualmente na elaboração do artigo.

\section{Disponibilidade de dados}

Os dados desta pesquisa estão disponíveis em: https://data.scielo.org/dataverse/brcp

\section{Como citar este artigo}

Karruz, A. P., \& Mello, C. (2021). Aspirações pelo ensino superior público e a Lei das Cotas. Cadernos de Pesquisa, 51, Artigo e07274. https://doi.org/10.1590/198053147274 